\title{
All-trans Retinoic Acid Is Increased in the Acute Phase-Related Hyporetinemia During Escherichia coli Mastitis
}

\author{
V. Van Merris, ${ }^{1}$ E. Meyer, ${ }^{1}$ L. Duchateau, ${ }^{1}$ J. Blum, ${ }^{2}$ and C. Burvenich ${ }^{1}$ \\ ${ }^{1}$ Department of Physiology, Biochemistry and Biometrics, \\ Faculty of Veterinary Medicine, Ghent University, B-9820 Merelbeke, Belgium \\ ${ }^{2}$ Division of Nutritional Pathology, Faculty of Veterinary Medicine, \\ University of Berne, $\mathrm{CH}-3012$ Berne, Switzerland
}

\begin{abstract}
Blood vitamin A profiles, including concentrations of retinol and its active metabolite retinoic acid, were assessed during the peripartum period and during experimentally induced Escherichia coli mastitis in heifers. Serum retinol decreased in all animals in the immediate postpartum period and normalized within $1 \mathrm{wk}$ after parturition. No significant changes were detectable in the concentrations of retinoic acid isomers during puerperium. Following intramammary $E$. coli infusion, all cows showed moderate symptoms of systemic disease besides the local signs of inflammation. The presence of a systemic acute-phase reaction was documented by fever, increase in serum amyloid A, and decrease in serum albumin. Retinol concentration in serum also decreased spectacularly during coliform mastitis, and the decline was clearly related to the timing of the acute-phase response. Moreover, a significant increase of all-trans retinoic acid, mirrored by a lowering of 13-cis retinoic acid, was detected during the same time period. The 9-cis isomer of retinoic acid was present in all samples, but it remained below the quantification limit.

Results confirmed the decrease in serum retinol during the peripartum period of dairy cows. Furthermore, the study established that profound changes in vitamin A metabolism occur during the acute-phase reaction of coliform mastitis in heifers. The bovine infection model reproduced the acute phase-related hyporetinemia, as previously observed in humans and rats. In addition, all-trans retinoic acid was found to be the most abundant circulating acid isomer during mastitis, providing an indication for a possible key role of all-trans retinoic acid in the modulation of the immune response.
\end{abstract}

(Key words: retinoic acid, peripartum period, Escherichia coli mastitis, acute-phase response)

Received July 11, 2003.

Accepted September 29, 2003.

Corresponding author: C. Burvenich; e-mail: Christian. Burvenich@UGent.be.

\begin{abstract}
Abbreviation key: 13cisRA = 13-cis retinoic acid, atRA = all-trans retinoic acid, p.i. = postinfusion, $\mathbf{R O H}=$ retinol, SAA $=$ serum amyloid A, TNF- $\alpha=$ tumor necrosis factor $\alpha$
\end{abstract}

\section{INTRODUCTION}

The importance of vitamin $\mathrm{A}$ in immune function and protection against infections is well established (Semba, 1998; Stephensen, 2001). Recent experiments using various animal models and cell lines suggest that retinoids modulate a variety of processes, including hematopoiesis, apoptosis, cytokine and immunoglobin production, and leukocyte function (Semba, 1998). Retinol (ROH) represents the most abundant retinoid in blood, whereas retinyl esters (particularly palmitate) represent the most abundant storage form in the liver. The major established pathway of enzymatic retinoid activation involves hydrolysis of retinyl ester, reversible oxidation of the released $\mathrm{ROH}$ into retinal, and irreversible oxidation of retinal to retinoic acid (Blaner and Olson, 1994). The immunologic effects of vitamin A appear to be mediated primarily through its acid derivatives, which include all-trans retinoic acid and 9cis retinoic acid (Petcovich et al., 1987).

Serum $\mathrm{ROH}$ levels are maintained within a fairly narrow range despite large fluctuations in dietary vitamin A intake and tissue stores. Only under extreme conditions, such as deficiency or intoxication, the homeostatically regulated $\mathrm{ROH}$ levels become affected. In humans, however, serum ROH concentrations were shown to decrease transiently during the acute-phase response to infection (Beisel, 1998; Mitra et al., 1998; Schweigert, 2001). This phenomenon can complicate the interpretation of serum $\mathrm{ROH}$ as an indicator of vitamin A status, and the concomitant assessment of acute-phase proteins seems therefore inevitable. Until now, little attention has been drawn towards the possible involvement of retinoic acid, the active metabolite of vitamin A, during infection and inflammation.

A variety of animal models, most of them involving rodents, have been used to study inflammatory diseases 
and have been described in the literature. However, controlled infection and disease with living bacteria is rather difficult in these small animal species (Vandeputte-Van Messom et al., 1995). In recent years, cow models were developed to study the systemic inflammatory response induced by mammary tissue infection (Burvenich et al., 1988). The success of these models is widespread because of their reproducibility, high selfcuring rate, and the facility to obtain samples allowing molecular, immunocytochemical, and pharmacological studies. Moreover, the severity of the systemic signs following IMI of cows with Escherichia coli can be standardized depending on the stage of lactation (Hirvonen et al., 1999) and parity (Mehrzad et al., 2002). A moderate level of systemic signs after intramammary $E$. coli infection can be obtained during midlactation, whereas a severe systemic response, sometimes leading to shock and death, is more prominent during early lactation. Older cows also show a large variation in severity during early lactation, whereas a moderate level of systemic signs is observed in heifers (Mehrzad et al., 2002). Severity classification can be obtained easily and accurately through measurement of the milk production in uninfected glands (Heyneman et al., 1990; VandeputteVan Messom et al., 1993) and is related to the increase in serum amyloid A (SAA; Hirvonen et al., 1999) and intensity of bacterial growth in the infected glands (Kremer et al., 1993).

This study was designed to define the blood vitamin A profile during the peripartum period and experimentally induced $E$. coli mastitis in heifers. Based on the hypothesis of a compensatory change in retinoid metabolism during inflammation, we especially focused on the retinoic acid isomers, the biologically active forms of vitamin A. For this purpose, a well-defined bovine IMI model with measurable but moderate level of systemic signs was used. Under these well-defined conditions, inference from the results is expected because the inflammatory response is a well-conserved process among vertebrates (Klasing et al., 1987).

\section{MATERIALS AND METHODS}

\section{Experimental Design}

Animals and housing. Eight clinically healthy Holstein-Friesian cows, each in her first pregnancy, were selected. All heifers were in their seventh month of pregnancy on arrival at the dairy farm. The heifers were on a system of zero grazing from arrival until the end of the experimental study. The course of calving was normal; no inflammatory processes were detected during puerperium. Animals were fed twice daily with a ration consisting of corn silage, apple pulp, hay, and water ad libitum. Concentrates (Sandilac; Dumoulin
Voeders Sanders, Moorslede, Belgium) were distributed according to milk production. Machine milking was performed daily at 0800 and $1800 \mathrm{~h}$, using a quarter milking device (Packo \& Fullwood, Zedelgem, Belgium). The study was approved by the Ethical Committee of the Faculty of Veterinary Medicine (Merelbeke, Ghent University).

Inoculation procedure. Heifers were in their second to fourth week of lactation when challenge was performed. Before the intramammary $E$. coli challenge, animals were controlled to be free of major mastitis pathogens through 2 consecutive negative bacteriological examinations with a milk SCC below 200,000 cells/ $\mathrm{mL}$ on quarter level. A stock of Escherichia coli strain P4:032 (Bramley, 1976) was maintained in lyophilization medium at $-20^{\circ} \mathrm{C}$. For experimental use, bacteria were subcultured in brain-heart infusion broth (CM225; Oxoid, Nepean, ON, Canada) at $37^{\circ} \mathrm{C}$ during 3 consecutive days. The bacterial suspension was washed 3 times and finally resuspended in pyrogenfree PBS. On d 0, after morning milking, 6 cows were inoculated in the left front and rear quarters with a suspension containing $1.10^{6}$ cfu of $E$. coli $\mathrm{P} 4: 032$ in a total volume of $10-\mathrm{mL}$ pyrogen-free saline solution per quarter. Following disinfection of the teat ends with $70 \%$ ethanol containing $0.5 \%$ chlorhexidine, the bacterial suspension was inoculated into the teat cistern by means of a sterile teat cannula. After inoculation, the left quarters were massaged for $30 \mathrm{~s}$ to distribute the bacterial suspension in the mammary gland.

\section{Sampling Procedure}

Blood samples were drawn aseptically from the external jugular vein by venipuncture, either in evacuated tubes containing $143 \mathrm{IU}$ of heparin or in plain tubes wrapped in foil (BD Vacutainer Systems, Plymouth, UK). Serum was obtained from clotted blood following incubation for $2 \mathrm{~h}$ at $37^{\circ} \mathrm{C}$ and subsequent centrifugation ( $\left.1000 \mathrm{rpm}, 30 \mathrm{~min}, 4^{\circ} \mathrm{C}\right)$. Serum samples were frozen at $-20^{\circ} \mathrm{C}$ until analysis.

Partus study. Daily samples from each cow were collected for metabolic profile assay beginning $2 \mathrm{~d}$ before the expected calving date and continuing for $1 \mathrm{wk}$ into lactation. Concentrations of retinoids, SAA and tumor necrosis factor $\alpha$ (TNF- $\alpha$ ) were determined in serum.

Mastitis study. Blood and milk samples were collected once daily on $d-7,-4,-1,0,+1,+2,+3,+6,+9$, and +13 relative to challenge. On the day of challenge (d 0), blood and milk samples were collected at 6,12 , and $18 \mathrm{~h}$ postinfusion (p.i.). Whole blood was used to determine the total blood leukocyte count. Retinoid, SAA, and albumin concentrations were quantified in 
serum. Somatic cell count and colony-forming units of $E$. coli were assessed in milk.

\section{Experimental Procedures}

Serum retinoid concentrations. As a precaution to avoid photoisomerization, all sample manipulations were carried out in amberized tubes under dim yellow light. Retinoid analogues were analyzed simultaneously by high-pressure liquid chromatography-diode array detection, using the liquid-liquid extraction and mobile phase conditions as described by Van Merris et al. (2002). Briefly, following acidification of the serum, proteins were denatured with acetonitrile. $\mathrm{ROH}$, alltrans (atRA), 9-cis and 13-cis retinoic acid (13cisRA) were extracted using a mixture of $n$-hexane and 2-propanol (6.5:1.5, vol/vol). The organic layer was evaporated, the residue dissolved, and retinoids were eluted on a Symmetry $\mathrm{C}_{18}$ column (Waters Corporation, Milford, MA). Serum retinoid concentrations were calculated from the chromatographic peak area ratios of each retinoid to the internal standard.

SAA and albumin. Serum amyloid A was determined by a commercial sandwich type ELISA kit (Phase SAA kit, Tridelta Development Ltd, Ireland) according to the manufacturer's instructions. Serum albumin was quantified using radial immunodiffusion plates (Bethyl, Montgomery, TX), based on the Fahey and McKelvey (1965) technique. All samples were run in duplicate.

$\boldsymbol{T N F}-\alpha$. Concentrations of TNF- $\alpha$ in blood serum were measured by radioimmunoassay (Blum et al., 2000).

Total blood leukocyte count. The number of circulating leukocytes was counted in an electronic particle counter (Coulter Counter Z2; Coulter Electronics Ltd., Luton, England).

Quarter milk production. Daily quarter milk production, the yield of the evening and subsequent morning milking, was measured daily using a quarter milking device (Packo \& Fullwood). The loss in milk production in the uninfected contralateral quarters on $\mathrm{d} 2 \mathrm{p}$.i. has been used as a criterion to classify cows as moderate or severe responders to experimental $E$. coli mastitis after parturition (Heyneman et al., 1990; VandeputteVan Messom et al., 1993).

Milk SCC. Milk SCC was determined using a fluoroopto electronic method (Fossomatic 400 cell counter; Foss Electric, Hillerød, Denmark), which is based on the binding of ethidium bromide to DNA.

Colony-forming units in the inoculated quarters. The population level of $E$. coli in the infused quarters was determined by 10 -fold dilutions of the milk sample in PBS. Ten microliters of the dilutions was plated out in duplicate on Columbia Sheep Blood agar
(Biokar Diagnostics, Beauvois, France) and incubated at $37^{\circ} \mathrm{C}$ for $24 \mathrm{~h}$. The obtained colony count was converted to colony-forming units per milliliter, based on the dilution factor.

\section{Statistical Analysis}

Partus study. A mixed model of SAS (version 8) was fitted to the retinoid, SAA, and TNF- $\alpha$ concentrations, respectively, with a day around parturition as the fixed categorical effect and cow as the random effect. The relationship between retinoid and SAA or TNF- $\alpha$ concentrations was investigated by a mixed model with SAA or TNF- $\alpha$ concentration as a continuous variable parameter and cow as a random effect. The association between retinoid and SAA or TNF- $\alpha$ concentration was expressed in terms of the slope (and its standard error), which corresponded to the change in retinoid concentration for a unit increase in SAA or TNF- $\alpha$, respectively.

Mastitis study. The sampling period was grouped into 3 time periods: the preinfection period comprising $\mathrm{d}-7,-4,-1$, and 0 ; the acute-phase period comprising $\mathrm{d}$ 0 , at 6,12 , and $18 \mathrm{~h}$ p.i., and $\mathrm{d}+1$; and the convalescence period comprising $d+2,+3,+6,+9$, and +13 . A mixed model of SAS (version 8) was fitted to the retinoid concentrations and protein concentrations, respectively, with period (3 levels: preinfection, acute phase, and convalescence) as the fixed effect and cow as the random effect to account for the repeated measures structure. Pairwise comparisons between the 3 periods were performed, adjusting the overall $95 \%$ confidence level by Tukey's multiple comparisons technique. The relationship between retinoid and protein (SAA and albumin) concentrations was investigated by a mixed model with protein concentration as a continuous fixed effect and again cow as the random effect. The association between the retinoid and protein concentration was expressed in terms of the slope (and its standard error), which corresponded to the change in retinoid concentration for a unit increase in protein concentration. A significant relationship corresponded to a slope being significantly different from 0 . Finally, the effect of retinoid concentrations in the acute-phase period on the reduction in milk production (related to mastitis severity) was studied by a fixed effect model.

\section{RESULTS}

\section{Partus Study}

Retinoid concentrations during the peripartum period. Throughout the partus study period, $\mathrm{ROH}$ and 2 retinoic acid isomer metabolites (atRA, 13cisRA) were detected in all samples at a sufficient level for quantification. The 9-cis isomer was present in all samples, but 

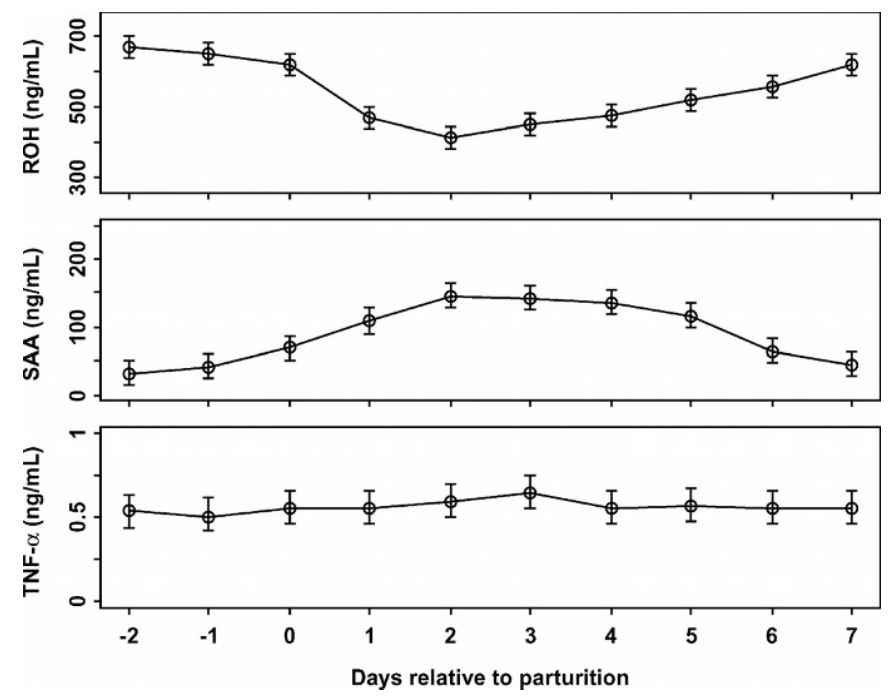

Figure 1. Serum retinol (ROH), serum amyloid A (SAA), and tumor necrosis factor $\alpha$ (TNF- $\alpha$ ) concentrations during the peripartum period. Data are means \pm SE of 8 cows.

it remained below the limit of quantification (i.e., $3 \mathrm{ng} /$ $\mathrm{mL}$ ). In all animals, serum $\mathrm{ROH}$ concentrations changed significantly $(P<0.0001)$ with time over parturition. Retinol values reached their minimal value on d 1 or d 2 after calving, started to reestablish by d 3 postpartum, and normalized within 1 wk (Figure 1). No significant fluctuations were observed in the concentrations of atRA and 13cisRA during the peripartum period.

SAA and TNF- $\alpha$ concentrations during the peripartum period. Parturition induced a significant increase in SAA concentration $(P<0.0001)$. Maximal values were detected in the immediate peripartum period and returned to baseline values within 1 wk after parturition. Fluctuations were observed in the concentrations of TNF- $\alpha$ during the peripartum period, although no significant differences were detected (Figure 1).

Relation between retinoid and SAA or TNF- $\alpha$ concentrations. A significant linear relationship existed between SAA and serum $\mathrm{ROH}$ concentrations with each unit increase in SAA concentration $(1 \mathrm{mg} / \mathrm{L})$ leading to a decrease of $1.41 \mathrm{ng} / \mathrm{mL}$ of $\mathrm{ROH}$ (slope $=-1.41$, $\mathrm{SE}=0.123$, and $P<0.0001$ ). There was no significant association between serum $\mathrm{ROH}$ and TNF- $\alpha$ concentrations during the peripartum period.

\section{Mastitis Study}

Characteristics of heifers with acute $E$. coli mastitis. Following intramammary $E$. coli infusion, all 6 heifers became ill, suffering from acute coliform mastitis. Clinical signs of inflammation (i.e., rubor, tumor,
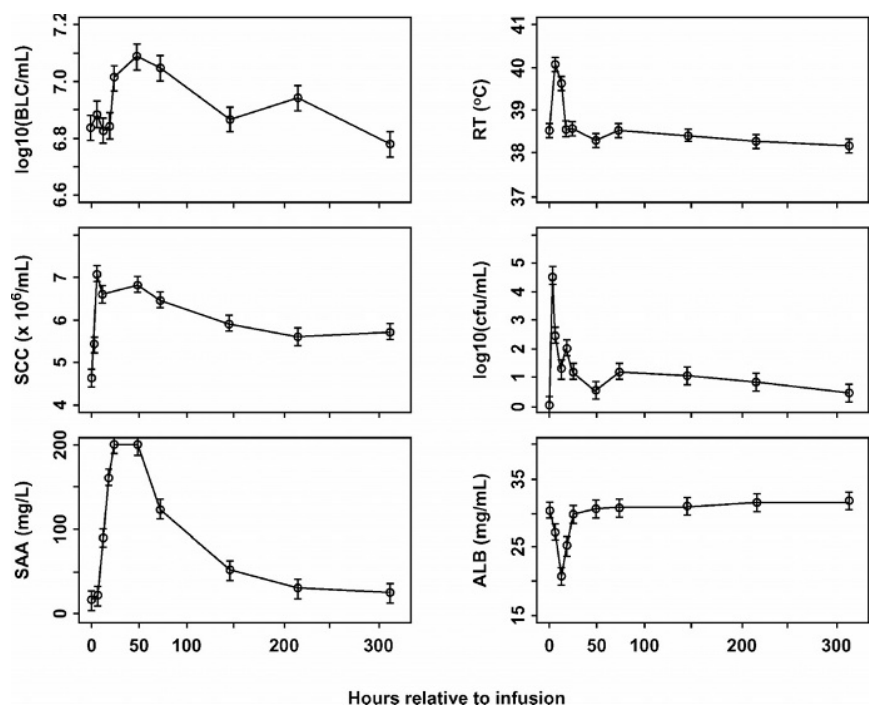

Figure 2. Characteristics of heifers with acute Escherichia coli mastitis: blood leukocyte count (BLC), rectal temperature (RT), colony forming units (CFU) of $E$. coli, somatic cell count (SCC), serum amyloid A (SAA), and albumin (ALB). Data are means $\pm \mathrm{SE}$ of 6 cows.

calor, dolor, and functio laesa) were present at the infection site. Furthermore, animals showed moderate signs of systemic disease and all cured spontaneously (Figure 2 ). The number of circulating leukocytes decreased during the acute-phase reaction. This initial leukopenia (6, 12 , and $18 \mathrm{~h}$ p.i.) was counteracted by a leukocytosis lasting until 6 d p.i., whereafter total blood leukocyte counts returned to preinfection values. Milk SCC increased spectacularly at $6 \mathrm{~h}$ p.i., remaining high during the convalescence period. The number of colony-forming units of $E$. coli in the infected quarters was elevated at $6 \mathrm{~h}$ p.i., where after the number of colony-forming units gradually decreased. Rectal temperature peaked at $6 \mathrm{~h}$ p.i. $\left(40.07 \pm 0.13^{\circ} \mathrm{C}\right)$, was still elevated at $12 \mathrm{~h}$ p.i., and normalized at $18 \mathrm{~h}$ p.i. The mean SAA concentration in the acute-phase period was 10-fold higher than during the preinfection period. The maximal concentration of SAA was reached at d 1 p.i. During the convalescence period, mean SAA decreased, but it was still elevated compared with the preinfection value. Mean albumin concentration decreased significantly during the acute-phase period, with the lowest concentration to be found at $12 \mathrm{~h} \mathrm{p}$.i. Concentrations of albumin normalized during convalescence (Table 1).

Retinoid concentrations during $E$. coli mastitis. Throughout the mastitis study period, $\mathrm{ROH}$ and 2 retinoic acid isomer metabolites (atRA and 13cisRA) were detected in all samples at a sufficient level for quantification (Table 1, Figure 3). The 9-cis isomer was present in all samples, but it remained below the limit of quantification. Serum $\mathrm{ROH}$ concentrations started to decrease 
Table 1. Serum amyloid A (SAA), albumin, and serum retinoid concentrations during 3 time periods of acute coliform mastitis in heifers. Preinfection period comprised $\mathrm{d}-7,-4,-1$, and 0 ; the acute-phase period comprised $\mathrm{d} 0$, at 6,12 , and $18 \mathrm{~h}$ p.i., and $\mathrm{d}+1$; and the convalescence period comprised $d+2,+3,+6,+9$, and +13 . Results are means (SE) of 6 animals.

\begin{tabular}{llrr}
\hline & Period & Concentration & $P$-value \\
\hline SAA $(\mathrm{mg} / \mathrm{L})$ & Preinfection & $13.73(8.15)$ & $<0.0001^{1}$ \\
& Acute-phase & $118.39(8.03)$ & $<0.0001^{2}$ \\
& Convalescence & $86.01(8.20)$ & $<0.0001^{3}$ \\
Albumin $(\mathrm{mg} / \mathrm{mL})$ & Preinfection & $30.08(1.20)$ & $<0.0001^{1}$ \\
& Acute-phase & $25.58(1.20)$ & $<0.0001^{2}$ \\
& Convalescence & $31.03(1.20)$ & $0.0122^{3}$ \\
Retinol (ng/mL) & Preinfection & $588.20(33.62)$ & $<0.0001^{1}$ \\
& Acute-phase & $436.92(33.62)$ & $<0.0001^{2}$ \\
& Convalescence & $544.41(33.29)$ & $0.0023^{3}$ \\
All-trans retinoic & & & \\
acid (ng/mL) & Preinfection & $3.08(0.33)$ & $<0.0001^{1}$ \\
& Acute-phase & $4.26(0.33)$ & $<0.0001^{2}$ \\
& Convalescence & $3.19(0.33)$ & $0.1186^{3}$ \\
13-cis retinoic & & & \\
acid (ng/mL) & Preinfection & $3.72(0.27)$ & $<0.0001^{1}$ \\
& Acute-phase & $2.70(0.27)$ & $<0.0001^{2}$ \\
& Convalescence & $3.47(0.27)$ & $0.0003^{3}$ \\
\hline
\end{tabular}

${ }^{1}$ Preinfection period compared with acute-phase period.

${ }^{2}$ Acute-phase period compared with convalescence period.

${ }^{3}$ Convalescence period compared with preinfection period.

at $6 \mathrm{~h}$ p.i., reaching the nadir at $\mathrm{d} 1$ p.i. During the convalescence period, $\mathrm{ROH}$ concentrations increased significantly but remained below preinfection levels. In contrast, atRA concentrations increased significantly during the acute-phase reaction, starting at $6 \mathrm{~h}$ p.i. and reaching maximal values at $12 \mathrm{~h}$ p.i. During the convalescence period atRA levels decreased signifi-
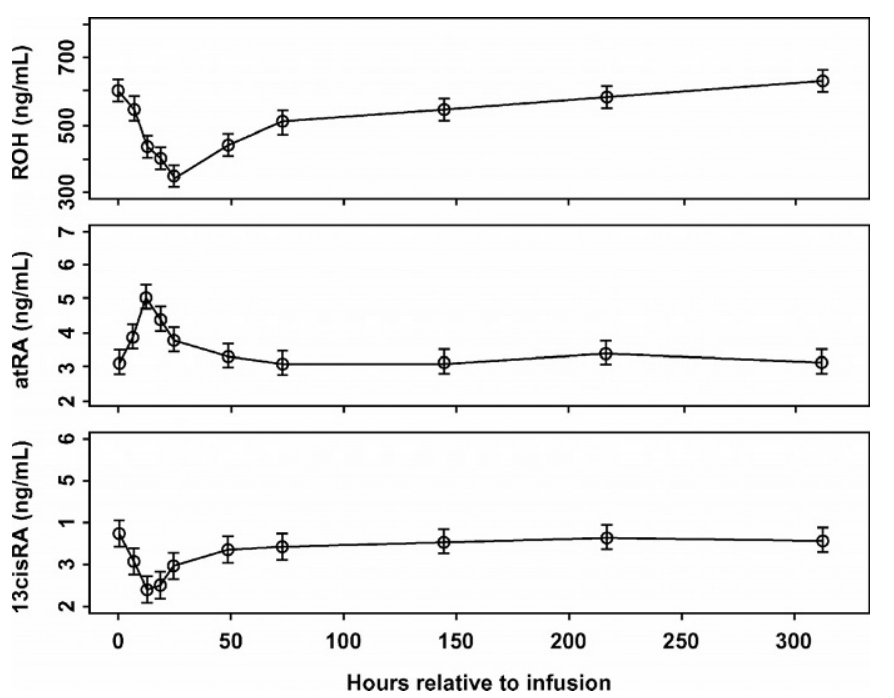

Figure 3. Serum retinoid concentrations of retinal $(\mathrm{ROH})$, alltrans retinoic acid (atRA), and 13-cis retinoic acid (13cisRA) during experimentally induced $E$. coli mastitis. Data are means $\pm \mathrm{SE}$ of 6 cows. cantly compared with the acute-phase period and returned to preinfection values. Remarkably, 13cisRA concentrations mirrored those of the all-trans analogue. Concentrations of 13cisRA started to decrease at $6 \mathrm{~h}$ p.i., reaching a dip at $12 \mathrm{~h}$ p.i. During the convalescence period 13cisRA increased but did not reach the preinfection values.

Relation between retinoid concentrations and acute-phase proteins. A significant linear relationship existed between SAA and serum ROH concentrations, with each unit increase in SAA concentration (1 $\mathrm{mg} / \mathrm{L}$ ), leading to a decrease of $1.12 \mathrm{ng} / \mathrm{mL}$ of $\mathrm{ROH}$ (slope $=-1.12, \mathrm{SE}=0.087$, and $P<0.0001$ ). The increase in SAA was concomitant with the decrease in $\mathrm{ROH}$, both reaching their maximal, respectively minimal concentration at d 1 p.i. Albumin concentration was negatively related with atRA concentration (slope $=-0.142$, $\mathrm{SE}=0.012$, and $P<0.0001$ ), whereas albumin was positively related with 13cisRA (slope $=0.099, \mathrm{SE}=$ 0.011 , and $P<0.0001$ ). The changes in albumin and both retinoic acid isomers were also concomitant: albumin and atRA reaching their maximal value at $12 \mathrm{~h}$ p.i., and 13cisRA showing the minimal concentration at the same timepoint.

Relationship between retinoid concentrations and severity of coliform mastitis. Based on the criterion of Heyneman et al. (1990) and Vandeputte-Van Messom et al. (1993), all 6 cows were classified as "moderate" responders. The reduction in milk production in the noninfected quarters on $\mathrm{d} 2$ p.i. was related to the 13cisRA concentration during the acute-phase reaction, with a decrease of $0.053 \mathrm{ng} / \mathrm{mL}$ of 13cisRA for each percentage reduction in milk production (slope = $-0.053, \mathrm{SE}=0.018$, and $P=0.0412$ ).

\section{DISCUSSION}

Serum concentrations of vitamin A derivatives were determined during the peripartum period ( $2 \mathrm{~d}$ before until $7 \mathrm{~d}$ after parturition) and during experimentally induced $E$. coli mastitis (from $7 \mathrm{~d}$ before challenge to $13 \mathrm{~d}$ p.i.). In addition to the classical $\mathrm{ROH}$ determination, the chromatographic set-up (Van Merris et al., 2002) allowed the simultaneous quantification of 3 retinoic acid isomers in bovine serum.

We were able to confirm the important decline in serum $\mathrm{ROH}$ concentrations in the immediate postpartum period, as previously described in dairy cows by Johnston and Chew (1984) and Goff and Stabel (1990). Colostrum production accounts for the major portion of the decline in $\mathrm{ROH}$ after parturition, as demonstrated in a recent mastectomy study (Goff et al., 2002). We detected atRA and slightly higher 13cisRA concentrations in bovine serum during the periparturient period; 
the 9-cis isomer remained below the quantification limit. In analogy with Goff et al. (2002), concentrations of the acid metabolites atRA and 13cisRA were not affected by parturition in heifers. Although large variations were observed in the concentrations of serum TNF- $\alpha$, no uniform pattern with regard to parturition was detected. This is in accordance with data of Koets et al. (1998), but it is in contradiction with the in vitro study of Sordillo et al. (1995). The acute-phase protein SAA increased during the immediate postpartum period. It has been suggested that the synthesis and release of this protein is a consequence of normal uterine involution, endometrial degeneration, and tissue remodeling (Koets et al., 1998).

Experimentally induced coliform mastitis in dairy cows during early lactation caused sepsis, a systemic inflammatory response to an active infectious process (Bone et al., 1992). All heifers suffered from general illness, with clinical signs of quarter inflammation and moderate systemic symptoms. The presence of an acutephase response was documented by fever, initial leukopenia followed by leukocytosis, increase in SAA, and decrease of albumin in circulation. Interestingly, the acute-phase response was accompanied by a significant decrease in serum $\mathrm{ROH}$ during experimentally induced mastitis. This phenomenon is in accordance to the welldescribed acute phase-related hyporetinemia in humans (Beisel, 1998; Mitra et al., 1998; Schweigert, 2001) and rats (Rosales and Ross, 1998). Moreover, a significant increase of atRA and a decrease of 13cisRA were detected at the same timepoint as the minimal concentration of serum albumin.

The mechanism underlying the acute phase-related decrease in $\mathrm{ROH}$ is not yet fully elucidated, but a number of possibilities have been proposed (Schweigert, 2001; Stephensen, 2001): decreased mobilization and transport of $\mathrm{ROH}$ from the liver, excretion of $\mathrm{ROH}$ in the urine, and increased metabolic requirements. Assuming that the observed changes in $\mathrm{ROH}$ serum concentrations reflect an increased requirement, it is tempting to speculate on increased utilization of retinoids during infection. The most intensively discussed possibility is the consumption of circulating antioxidants during neutralization of free radicals caused by activation of neutrophils (Sies and Stahl, 1995).

The transient changes in retinoic acid isomers (the metabolically active forms of vitamin A) observed in the current study during acute coliform mastitis are remarkable and have not been previously described in literature. During the acute-phase reaction, the increase of atRA is largely mirrored by a lowering of 13cisRA. Retinoic acid signals are mediated by specific nuclear receptors, the retinoic acid receptors and retinoid X receptors, which are part of a complex signaling network, allowing for receptor-receptor and receptorDNA interaction (Petcovich et al., 1987). Because 13cisRA does not display a strong binding affinity for these retinoid receptors, it is believed that 13cisRA can act by serving as a precursor for the more transcriptionally active atRA (Blaner, 2001). Steric isomerization of 13cisRA to atRA, catalyzed by an isomerase, may thus be of importance to nuclear retinoid receptor-mediated biological activities. The different retinoic acid isomers have been shown to be enzymatically interconverted in a reversible way in vivo (Kojima et al., 1994).

Alternatively, the increase in atRA during the acutephase reaction can partially be attributed to substantial increases in the oxidation of $\mathrm{ROH}$ to atRA. A mechanism for this hypothesis can be provided by the knowledge of the metabolic steps catalyzed by retinoid dehydrogenases during conversion of $\mathrm{ROH}$ to retinoic acid. The first and rate-limiting step involves the reversible conversion of $\mathrm{ROH}$ into retinal by alcohol dehydrogenases; retinal is then irreversibly oxidized into atRA by $\mathrm{NADP}^{+}$-dependent aldehyde dehydrogenase(s) (Duester, 2000). Regulation of retinoic acid biosynthesis has not been fully elucidated, although prostaglandins may be modulatory at the site of conversion (Napoli, 1993). Nonetheless, our data strongly indicate a transient bioactivation mechanism (Chen and Juchao, 1998), possibly involving significant modifications in the activity of these dehydrogenases and putative isomerase during the acute-phase reaction. Some enzymes from the dehydrogenase families specialized in retinoid metabolism are known to be genetically highly conserved (Duester, 2000). Extrapolation of the present data, obtained during acute coliform mastitis in heifers, to other animal or human models seems therefore justified, although it can not be excluded that species-specific enzymes might also have contributed to our findings.

Whereas the reduction in serum $\mathrm{ROH}$ may reflect increases in general consumptive or oxidative processes, there is no clear evidence to suggest that the reduction has any relationship with the outcome of the animal (Schweigert, 2001), whereas such an association was found for serum 13cisRA concentrations. The changes in serum retinoid levels may either have an important causal relationship with the outcome or may simply represent secondary phenomena. The former suggestion would provide a strong argument for the supplementation of vitamin A in dairy cows during the peripartum period, as it may reduce the incidence and severity of mammary infections (Chew et al., 1982; Johnston and Chew, 1984; Oldham et al., 1991).

The transient and self-correcting nature of the changes in vitamin A concentrations during coliform mastitis in heifers argues against a true deficiency state 
and indicates that acute infection influences the retinoid metabolism in far more complex ways than the simple depletion of vitamin A stores. In humans, it has previously been suggested that the serum ROH concentration that is reached during the acute phase of infection is due primarily to transient changes in vitamin A metabolism unrelated to total liver stores (Mitra et al., 1998). Furthermore, proportionately similar reductions in serum $\mathrm{ROH}$ in response to endotoxin were found in vitamin A-deficient and vitamin A-adequate rats (Rosales and Ross, 1998), indicating that the effect of inflammation on $\mathrm{ROH}$ concentration does not depend on vitamin A status.

\section{CONCLUSIONS}

In summary, this paper confirms the hyporetinemia observed in dairy cows during the immediate postpartum period. Furthermore, it describes the vitamin A profile during the acute-phase reaction of infection, using an $E$. coli-induced mastitis in heifers during early lactation. The cow model used in the study apparently reproduced the marked but transient reduction in serum $\mathrm{ROH}$, as observed during infection in humans and rats. In addition, atRA was shown to be the most abundant retinoic acid isomer during the acute-phase reaction of mastitis in bovine, providing evidence of a shift in retinoid metabolism towards the active metabolite. Although interactions between retinoids and important immune response factors such as immune cells, adhesion molecules, and cytokines have been postulated (Semba, 1998), the functional importance of the infection-induced changes in serum retinoid levels awaits further clarification. The present data show the involvement of atRA in the acute phase-related hyporetinemia and form a strong indication for the key role of atRA in modulating the immune response during infection.

\section{ACKNOWLEDGMENTS}

The authors are very grateful to $\mathrm{H}$. De Brabander for the use of the HPLC-DAD and to K. De Wasch for her excellent assistance. This study was supported by the Flemish Institute for the Encouragement of Research in the Industry (IWT-grant no. SB/993161 to V. Van Merris) and the Fund for Scientific Research (F.W.O.).

\section{REFERENCES}

Beisel, W. R. 1998. Infection-induced depression of serum retinola component of the acute phase response or a consequence? Am. J. Clin. Nutr. 68:993-994.

Blaner, W. S. 2001. Cellular metabolism and actions of 13-cis-retinoic acid. J. Am. Acad. Dermatol. 45:S129-S135.
Blaner, W., and J. Olson. 1994. Retinol and retinoic acid metabolism. Pages 229-255 in The Retinoids: Biology, Biochemistry, and Medicine. M. Sporn, A. Roberts, and D. Goodman, ed. Raven Press, New York, NY.

Blum, J., H. Dosogne, D. Hoeben, F. Vangroenweghe, H. Hammon, R. M. Bruckmaier, and C. Burvenich. 2000. Tumor necrosis factoralpha and nitrite/nitrate responses during acute mastitis induced by Escherichia coli infection and endotoxin in dairy cows. Domest. Anim. Endocrinol. 19:223-235.

Bone, R., R. Balk, F. Cerra, R. Dellinger, A. Fein, W. Knaus, R. Schein, and W. Sibbald. 1992. Definitions for sepsis and organ failure and guidelines for the use of innovative therapies in sepsis. Chest 101:1644-1655.

Bramley, A. J. 1976. Variations in the susceptibility of lactating and non-lactating bovine udders to infection when infused with Escherichia coli. J. Dairy Res. 43:205-211.

Burvenich, C., G. Vandeputte-Van Messom, R. Heyneman, A.-M. Massart-Leën, E. Roets, J. Fabry, and E. Kühn. 1988. The mammary gland as a model for the study of local and systemic inflammatory reactions. Pages 213-224 in Proc. of the 4th Congress of the European Association for Veterinary Pharmacology and Toxicology, Budapest, Hungary.

Chen, H., and M. R. Juchao. 1998. Biotransformation of 13-cis- and 9-cis-retinoic acid to all-trans-retinoic acid in rat conceptal homogenates. Evidence for catalysis by a conceptal isomerase. Drug Metab. Dispos. 26:222-228.

Chew, B. P., L. L. Hollen, J. K. Hillers, and M. L. Herlugson. 1982. Relationship between vitamin A and $\beta$-carotene in blood plasma and milk and mastitis in Holsteins. J. Dairy Sci. 65:2111-2118.

Duester, G. 2000. Families of retinoid dehydrogenases regulating vitamin A function. Eur. J. Biochem. 267:4315-4324.

Fahey, J. L., and E. M. McKelvey. 1965. Quantitative determination of serum immunoglobulins in antibody-agar plates. J. Immunol. 94:84-90.

Goff, J. P., K. Kimura, and R. L. Horst. 2002. Effect of mastectomy on milk fever, energy, and vitamins $\mathrm{A}, \mathrm{E}$, and $\beta$-carotene status at parturition. J. Dairy Sci. 85:1427-1436.

Goff, J. P., and J. R. Stabel. 1990. Decreased plasma retinol, $\alpha$ tocopherol, and zinc concentration during the periparturient period: Effect of milk fever. J. Dairy Sci. 73:3195-3199.

Heyneman, R., C. Burvenich, and R. Vercauteren. 1990. Interaction between the respiratory burst activity of neutrophil leukocytes and experimentally induced Escherichia coli mastitis in cows. J. Dairy Sci. 73:985-994.

Hirvonen, J., K. Eklund, A. M. Teppo, G. Huszenicza, M. Kulcsar, H. Saloniemi, and S. Pyörälä. 1999. Acute phase response in dairy cows with experimentally induced Escherichia coli mastitis. Acta Vet.Scand. 40:35-46.

Johnston, L. A., and B. P. Chew. 1984. Peripartum changes of plasma and milk vitamin $\mathrm{A}$ and $\beta$-carotene among dairy cows with or without mastitis. J. Dairy Sci. 67:1832-1840.

Klasing, K. C., M. P. Richards, S. E. Darcey, and D. E. Laurin. 1987. Presence of acute phase changes in zinc, iron, and copper metabolism in turkey embryos. Proc. Soc. Exp. Biol. Med. 184:7-13.

Koets, A. P., N. de Schwartz, P. Tooten, M. Kankofer, J. M. Broekhuijsen-Davies, V. P. M. G. Rutten, L. A. M. G. van Leengoed, M. A. M. Taverne, and E. Gruys. 1998. Release of pro-inflammatory cytokines related to luteolysis and the periparturient acute phase response in prostaglandin-induced parturition in cows. Theriogenology 49:797-812.

Kojima, R., T. Fujimori, N. Kiyota, Y. Toriya, T. Fukuda, T. Ohashi, T. Sato, Y. Yoshizawa, K. Takeyama, H. Mano, S. Masushige, and S. Kato. 1994. In vivo isomerization of retinoic acids. Rapid isomer exchange and gene expression. J. Biol. Chem. 269:32700-32707.

Kremer, W. D. J., E. N. Noordhuizen-Stassen, F. Grommers, A. Daemen, P. Henricks, A. Brand, and C. Burvenich. 1993. Preinfection chemotactic response of blood polymorphonuclear leukocytes to predict severity of Escherichia coli mastitis. J. Dairy Sci. 76:1568-1574.

Mehrzad, J., L. Duchateau, S. Pyörälä, and C. Burvenich. 2002. Blood and milk neutrophil chemiluminescence and viability in primipa- 
rous and pluriparous dairy cows during late pregnancy, around parturition and early lactation. J. Dairy Sci. 85:3268-3276.

Mitra, A. K., J. O. Alvarez, M. A. Wahed, G. J. Fuchs, and C. B. Stephensen. 1998. Predictors of serum retinol in children with shigellosis. Am. J. Clin. Nutr. 68:1088-1094.

Napoli, J. L. 1993. Prostaglandin E and 12-O-tetradecanoylphorbol13-acetate are negative modulators of retinoic acid synthesis. Arch. Biochem. Biophys. 300:577-581.

Oldham, E. R., R. J. Eberhart, and L. D. Muller. 1991. Effects of supplemental vitamin A or $\beta$-carotene during the dry period and early lactation on udder health. J. Dairy Sci. 74:3775-3781.

Petcovich, M., J. B. Nigel, A. Krust, and P. Chambon. 1987. A human retinoic acid receptor which belongs to the family of nuclear receptors. Nature (Lond.) 330:444-450.

Rosales, F. J., and A. C. Ross. 1998. Acute inflammation induces hyporetinemia and modifies the plasma and tissue response to vitamin A supplementation in marginally vitamin A-deficient rats. J. Nutr. 128:960-966.

Schweigert, F. J. 2001. Inflammation-induced changes in the nutritional biomarkers serum retinol and carotenoids. Curr. Opin. Clin. Nutr. Metab. Care 4:477-481.

Semba, R. D. 1998. The role of vitamin A and related retinoids in immune function. Nutr. Rev. 56:S38-S48.
Sies, H., and W. Stahl. 1995. Vitamins E and C, beta-carotene, and other carotenoids as antioxidants. Am. J. Clin. Nutr. 62:S1315-S1321.

Sordillo, L. M., G. M. Pighetti, and M. R. Davis. 1995. Enhanced production of bovine tumor necrosis factor- $\alpha$ during the periparturient period. Vet. Immunol. Immunopathol. 49:263-270.

Stephensen, C. B. 2001. Vitamin A, infection, and immune function. Annu. Rev. Nutr. 21:167-192.

Van Merris, V., E. Meyer, K. De Wasch, and C. Burvenich. 2002. Simple quantification of endogenous retinoids in bovine serum by high-performance liquid chromatography-diode-array detection. Anal. Chim. Acta 468:237-244.

Vandeputte-Van Messom, G., C. Burvenich, E. Roets, L. Devriese, and F. Haesebrouck. 1995. Effects of Staphylococcus aureus mastitis after endotoxin application on milk yield and composition during subsequent lactation of guinea-pigs. Zentralbl. Veterinarmed. B 42:118-126.

Vandeputte-Van Messom, G., C. Burvenich, E. Roets, A.-M. Leën, R. Heyneman, W. D. J. Kremer, and A. Brand. 1993. Classification of newly calved cows into moderate and severe responders to experimentally induced Escherichia coli mastitis. J. Dairy Res. 60:19-29. 